\title{
Main Diesel Engine Selection for Ships Based on Life Cycle Costing
}

$$
\text { Jun-Bao Geng }{ }^{1,2, a} \text {, Jing-Biao Cai }{ }^{3, b} \text {, Mei-Jie Luo }{ }^{1,2, c} \text {, Jian-Zhao Niu }{ }^{1,2, d}
$$

${ }^{1}$ Military Key Laboratory for Naval Ship Power Engineering, Naval University of Engineering, Wuhan 430033, Hubei, China

${ }^{2}$ College of Power Engineering, Naval University of Engineering, Wuhan 430033, Hubei, China

${ }^{3}$ Beijing 1303 Mail Box 14 Box, Beijing 100161, China

agengjb2002@163.com, bjingbiaocai@sina.com, ‘413825902@qq.com, d13135688436@163.com

Keywords: Main diesel engine, Life cycle costing, Decision-making.

\begin{abstract}
In order to obtain optimum decision making in selecting main diesel engine for ships, the life cycle cost technology is proposed. The breakdown structure and calculation model of life cycle cost for main diesel engine of ships are established. Taking a specific selection for main diesel engine of one ship as the instance, the purchase cost and life cycle cost for three types of main diesel engine are compared and analyzed. The type of main diesel engine is selected based on the calculation result of life cycle cost. The instance shows that the life cycle cost technology is a powerful decision-making tool, which is worthy of popularization and application in ship design and development stages.
\end{abstract}

\section{Introduction}

In the process of ship design, main diesel engine selection is very important. Selection for main diesel engine is affected by many factors, such as the rated power, rated revolutions per minute, fuel consumption, purchase price, weight and size, life, maintenance cost, and so on. For some ship, many kinds of main diesel engines can be chosen at the beginning of the design. Some diesel engines are expensive, but they have high reliability and low fuel consumption. Some diesel engines are cheap, but they have high fuel consumption and failure rate, etc. It is proved that the life cycle cost technology is an economic powerful decision-making tool [1-7]. This paper will put forward that the main diesel engine will be chosen by life cycle cost technology. Life cycle cost model of main diesel engine is set up. The purchase cost and life cycle cost (LCC) for three types of main diesel engine are compared and analyzed for some special ship.

\section{The LCC breakdown structure of main diesel engine for ships}

According to cost breakdown method provided in the International Electro technical Standards IEC300-3 [4], the LCC breakdown structure of main diesel engine for ships is described in Fig. 1.

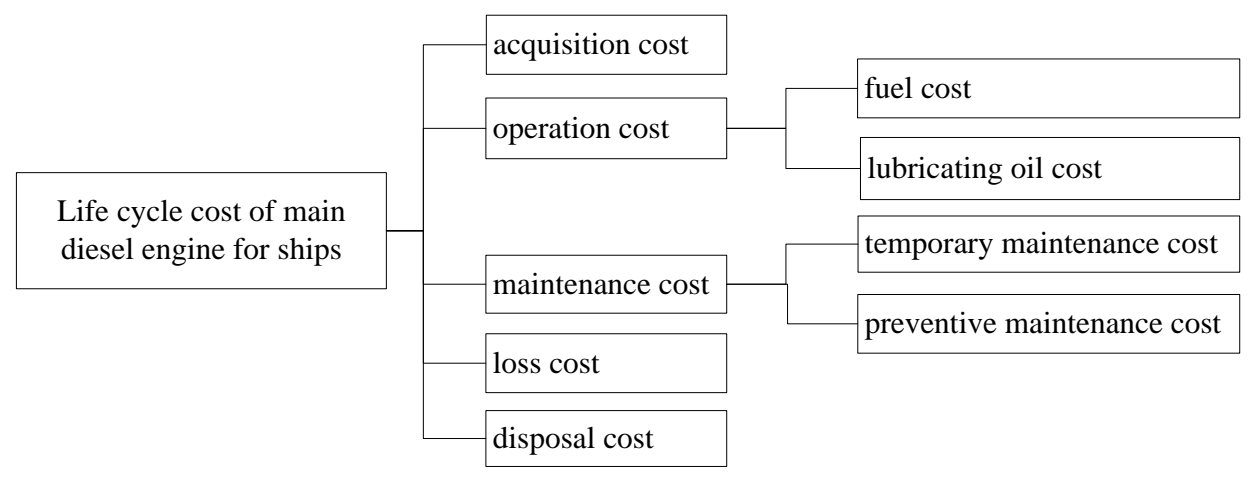

Fig. 1 The LCC breakdown structure of main diesel engine for ships 


\section{Acquisition cost $C_{P}$}

Acquisition cost refers to the cost used to obtain the main diesel engine, which includes the cost of the price, transportation and installation, initial guarantee spare parts and other costs.

\section{Operation cost $C_{U}$}

Operation cost refers to the energy costs, mainly including the cost of fuel and lubricating oil costs. Fuel cost is related to the main diesel engine's oil consumption rate, working time and oil price, etc.

\section{Maintenance cost $C_{M}$}

Maintenance cost refers to the costs needed to pay for the main diesel engine to restore or improve to a specified state. Maintenance can be divided into preventive maintenance, temporary maintenance. Preventive maintenance can be divided into the dock maintenance, minor maintenance and medium maintenance. Temporary maintenance can be divided into daily temporary maintenance and emergency maintenance.

\section{Loss cost $C_{L}$}

Loss cost mainly includes loss of business caused by the failure of the main diesel engine. The preventive maintenance does not cause loss cost.

\section{Disposal $\operatorname{cost} C_{R}$.}

Disposal cost refers to the cost used to deal with retired equipment. The disposal cost of the main engine system can be retrieved in $8 \%$ of the acquisition expense after retirement.

\section{The LCC model of ship diesel engine}

Assuming the annual average price index is $\gamma$, the bank average annual rate is $i$, annual average working hour of a ship is $T$, its unit is hour. The number of the main engine is $K$.

The LCC of the main engine is mainly composed of acquisition cost, operation cost, maintenance cost, loss cost and disposal cost. The LCC is given by

$$
L C C=C_{P}+C_{U}+C_{M}+C_{L}+C_{R}
$$

Where $C_{P}$ is the cost used to obtain the main engines in RMB; $C_{U}$ is operation cost of the main engines in RMB; $C_{M}$ is maintenance cost of the main engines in RMB; $C_{L}$ is loss cost caused by the failure of the main engines in RMB; $C_{R}$ is disposal cost for main engines after retirement.

\section{Operation cost $C_{U}$}

The main diesel engine operation cost in a year mainly includes the fuel cost and lubricating oil cost. The main diesel engine operation cost is given by

$$
C_{U Y}=\frac{T \times K \times E_{\mathrm{R}} \times W}{\rho_{\mathrm{R}}} \times C_{\mathrm{R}}+\frac{T \times K \times E_{\mathrm{H}} \times W}{\rho_{\mathrm{H}}} \times C_{\mathrm{H}}
$$

Where $C_{U Y}$ is annual average operation cost in RMB; $E_{\mathrm{R}}$ is average fuel consumption of single main diesel engine in $\mathrm{kg}$ per kilowatt; $W$ is the power of single main diesel engine in $\mathrm{kW} ; \rho_{\mathrm{R}}$ is fuel density in $\mathrm{kg}$ per liter; $C_{\mathrm{R}}$ is fuel unit price in yuan per liter; $E_{\mathrm{H}}$ is average lubricating oil consumption of single main diesel engine in $\mathrm{kg}$ per kilowatt; $\rho_{\mathrm{H}}$ is lubricating oil density in $\mathrm{kg}$ per liter; $C_{\mathrm{H}}$ is lubricating oil unit price in yuan per liter.

Consider the price index and the time value of the funds, the operation cost in $N$ years is given by 


$$
C_{U}=C_{U Y} \times \sum_{n=0}^{N} \frac{(1+\gamma)^{n}}{(1+i)^{n}}
$$

Where $C_{U}$ is the operation cost of the main diesel engines in their life; $C_{U Y}$ operation cost in RMB. $N$ is the number of the service time.

\section{Maintenance cost $C_{M}$}

Maintenance cost mainly consists of maintenance labor cost, maintenance equipment cost and spare parts cost. It is given by

$$
C_{M}=C_{M L}+C_{M C}
$$

Where $C_{M}$ is the maintenance cost of the main diesel engines in the whole life; $C_{M L}$ is the temporary cost of main diesel engine throughout the life cycle; $C_{M C}$ is the cost for an overhaul of single main diesel engine in the entire life. $C_{M L}$ is closely related to mean maintenance cost, mean time between failures, mean equipment work time, service time, price index, and interest rates. $C_{M L}$ is given by

$$
C_{M L}=\frac{T \times K}{M T B F} \times C_{F} \times \sum_{n=0}^{N} \frac{(1+\gamma)^{n}}{(1+i)^{n}}
$$

Where $M T B F$ is mean time between failures of single main diesel engine in hour; $C_{F}$ is the mean maintenance cost of single main diesel engine in yuan. $C_{M C}$ is related to mean overhaul interval time of single main diesel engine, average cost of main diesel engine overhaul once. It is given by

$$
C_{M C}=K \times C_{P M W} \times \sum_{n=1}^{m}\left(\frac{1+\gamma}{1+\mathrm{i}}\right)^{n_{m}}
$$

Where $C_{P M W}$ is average cost of main diesel engine overhaul once in yuan; $m$ is The number of the main diesel engine needed to overhaul during the service; $n$ is the index of the overhaul of main diesel engine; $n_{m}$ is the service time of the main diesel engine when the overhaul index is $m$ in year.

\section{Loss cost $C_{L}$}

If the time value of funds and the price index are considered temporarily, loss cost is given by

$$
C_{L}=\frac{K \times T}{M T B F} \times \frac{W \times K}{0.75} \times C_{L 0} \times M T T R
$$

Where $C_{L}$ is the loss cost caused by main diesel engines fault in yuan; $C_{L 0}$ is loss cost at unit time caused by the failures of main diesel engine unit power in yuan per hour, generally 10 yuan/horsepower; $W$ is The power of the single main diesel engine in $\mathrm{kW}$; $M T B F$ is mean time between failures of single main diesel engine in hours. If one main diesel engine fails, the ship will not be able to work; MTTR is the time that a ship cannot work caused by the failures of main diesel engine. 


\section{Disposal cost $C_{R}$}

The disposal cost of main diesel engine after retirement is given by

$$
C_{R}=-C_{P} \times \frac{(1+\gamma)^{N}}{(1+i)^{N}} \times 8 \%
$$

Where $C_{P}$ is the purchase cost of main diesel engine in yuan. $N$ is the number of the service time.

\section{A case of main diesel engine selection for a ship based on the LCC technology}

\section{Basic parameters}

A ship has two main diesel engines. The annual work time of each diesel engine is about 2000 hours. The density of the diesel is about $0.84 \mathrm{~kg}$ per liter and the density of the lubricating oil is about $0.90 \mathrm{~kg}$ per liter. The diesel costs about 5.8 yuan per liter and lubricating oil costs of about 60 yuan per liter. The service time of the ship is 33 years. Disposal cost of main engine after 33 years is $8 \%$. Loss cost is about 3000 yuan per hour. It is assumed that the price index is $4 \%$ and bank average annual rate is $3 \%$.

\section{Life profile of the ship}

Main diesel engine is mainly overhauled in ship preventive maintenance time, such as in dock repair, minor maintenance, or medium maintenance, in order to reduce the loss of the ship. Life profile is the description of the usage and maintenance action of the ship from the beginning to the end of the service. The profile of the ship is shown in Figure 2. According to "dock repair - minor repair - dock repair - medium repair" mode, there are five dock maintenances, two minor maintenances and two medium maintenances. Each task time is about 30 months. Dock repair time is about 3 months; minor repair time is about 6 months, and medium maintenance time is about 12 months.

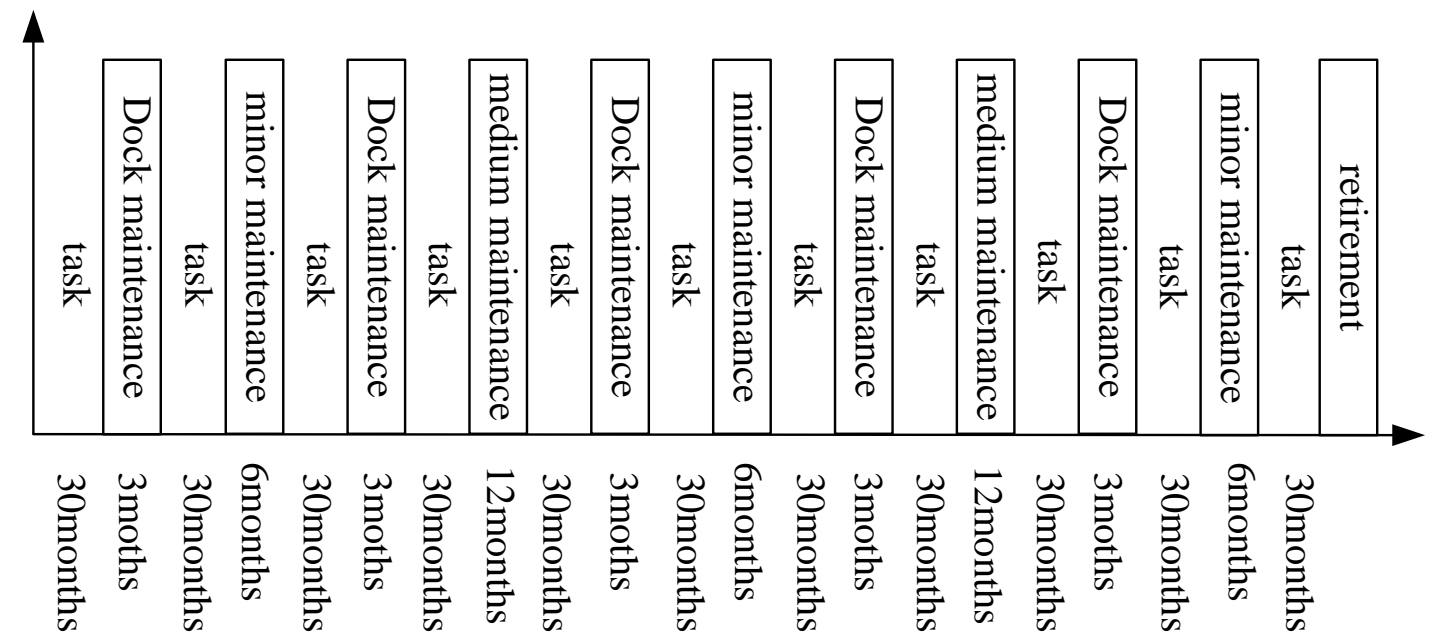

Fig.2 Life profile of the ship

\section{Main diesel engine alternatives}

The power of single main diesel engine is about 4000 horsepower, or about 3000 kilowatts. Considering the redundancy factor $10 \%$, the power of single main diesel engine can be about 3300 $\mathrm{kW}$. According to the investigation, three kinds of main engine is described in Table 1. 
Tab.1 Basic parameters of main diesel engine alternatives

\begin{tabular}{cccc}
\hline Parameter Name & Scheme 1 & Scheme 2 & Scheme 3 \\
\hline Maximum continuous power $(\mathrm{kW})$ & 3460 & 3300 & 3300 \\
Fuel consumption rate $(\mathrm{g} / \mathrm{kWh})$ & 185 & 188 & 190 \\
Fuel consumption $(\mathrm{g} / \mathrm{kWh})$ & 0.7 & 0.8 & 0.9 \\
MTBF $(\mathrm{h})$ & 3000 & 2000 & 1500 \\
The cost of the average maintenance time (yuan) & 10000 & 8000 & 8000 \\
MTTR (h) & 20 & 20 & 20 \\
The host machine overhaul interval (year) & 10 & 8 & 8 \\
Average cost of The host machine overhaul(ten \\
thousand yuan)
\end{tabular}

\section{Life cycle cost estimation results}

Calculation result of three schemes is listed in Table 2.

Tab.2 Life cycle cost in three schemes

\begin{tabular}{|c|c|c|c|}
\hline Parameter Name & Scheme 1 & Scheme 2 & Scheme 3 \\
\hline Maximum continuous power $(\mathrm{kW})$ & 3460 & 3480 & 3500 \\
\hline Fuel consumption rate (g/kWh) & 185 & 188 & 190 \\
\hline Fuel consumption (g/kWh) & 0.7 & 0.8 & 0.9 \\
\hline $\operatorname{MTBF}(\mathrm{h})$ & 3000 & 2000 & 1500 \\
\hline The cost of the mean maintenance time (yuan) & 10000 & 8000 & 8000 \\
\hline MTTR (h) & 10 & 10 & 10 \\
\hline The main engine machine overhaul interval (year) & 10 & 8 & 8 \\
\hline $\begin{array}{c}\text { Average cost of The main engine machine } \\
\text { overhaul(ten thousand yuan) }\end{array}$ & 46 & 32 & 32 \\
\hline $\begin{array}{l}\text { Acquisition expenses of whole system(ten thousand } \\
\text { yuan) }\end{array}$ & 2450 & 2000 & 1800 \\
\hline $\begin{array}{l}\text { Loss cost of per hour caused by main engine down } \\
\text { (yuan per hour) }\end{array}$ & 92267 & 92800 & 93333 \\
\hline Annual average working time of the ship (h) & 2000 & 2000 & 2000 \\
\hline Working cost(ten thousand yuan) & 70881 & 72765 & 74292 \\
\hline Temporary maintenance cost(ten thousand yuan) & 26 & 31 & 41 \\
\hline Plans to overhaul cost(ten thousand yuan) & 219 & 224 & 246 \\
\hline The total maintenance cost(ten thousand yuan) & 245 & 255 & 287 \\
\hline Loss cost(ten thousand yuan) & 2030 & 3062 & 4106 \\
\hline Expenses recovery(ten thousand yuan) & -267 & -218 & -196 \\
\hline LCC(ten thousand yuan) & 75339 & 77864 & 80289 \\
\hline
\end{tabular}

In Table 2, the following conclusions can be drawn: The purchase cost in Scheme 1 is the largest, more than the purchase cost of Scheme 24.5 million yuan, more than the purchase cost of plan 36.5 
million Yuan; Life cycle cost of Scheme 1 is 753.39 million yuan, less 25.25 million Yuan than Scheme 2, less 49.5 million yuan than Scheme 3. According to the estimation results, the design department sets up the main diesel engine selection scheme for ship-owners based on Scheme 1 .

\section{Summary}

This paper constructed the life cycle cost model of ship's main diesel engine, and the model was applied to main diesel engine selection of one ship. The case shows that the scheme with the least initial investment is not necessarily the one with the minimum life cycle cost, and the scheme with the largest initial investment is not necessarily the scheme with the maximum life cycle cost. By life cycle cost technology, the scheme with minimum life cycle cost can be obtained. Life cycle cost technology is a powerful tool for scientific decision-making, which is worth popularizing in ship design and development stages and application.

\section{References}

[1] D. Hunkeler, K. Lichtenvort and G. Rebitzer. Environmental life cycle costing. Boca Raton, Florida, U.S.: CRC Press, 2008.

[2] ISO 15686-5:2008, Buildings and constructed assets-service life planning-Part 5: life cycle costing. ISO, 2008.

[3] ISO 15663-1:2000, Petroleum and natural gas industries - life cycle costing - part 1: methodology. ISO, 2000.

[4] IEC 60300-3-3-2004, Dependability management-part 3-3: application guide- life cycle costing. International Electrotechnical Commission, 2004.

[5] B.S. Dhilion. Life cycle costing: Techniques models, and applications. New York: Gordon and Breach Science Publisher, 1989.

[6] Kirk S J and A J Dell'Isola. Life cycle costing for design professionals. New York: McGrew-Hill Book Company, 1995.

[7] B.S. Dhilion. Life cycle costing for engineers. Boca Raton, Florida: CRC Press, 2010. 